\title{
Émilie Du Châtelet and the foundations of physical science
}

\author{
Katherine Brading \\ kbrading@nd.edu
}

\begin{abstract}
Du Châtelet's 1740 text Foundations of Physics tackles three of the major foundational issues facing natural philosophy in the early eighteenth century: the problem of bodies, the problem of force, and the question of appropriate methodology. This paper offers an introduction to Du Châtelet's philosophy of science, as expressed in her Foundations of Physics, primarily through the lens of the problem of bodies.
\end{abstract}

\section{Introduction}

This paper is a written version of the talk that I gave at the British Society for the Philosophy of Science conference in July 2015. On the assumption that few people in the room would know much if anything about Du Châtelet's philosophy of science, the talk combined research involving her work with an introduction to Du Châtelet's Institutions de Physique (1740, hereafter translated as Foundations of Physics). The resulting patchwork contained a variety of elements several of which could be developed into scholarly papers, and that was my original intention. However, the feedback that I received following the talk has encouraged me to think that, rather than waiting for these individual scholarly papers, the patchwork itself provides a service in the interim. This paper is offered in that spirit. Inevitably, there is much that goes by too fast, and much that lacks adequate substantiation and argument. I have added some footnotes with the objective of offering entry points into relevant literature, but this falls short of providing a thorough bibliography. ${ }^{1}$ My hope is that these inadequacies will be forgiven, pending further more detailed papers by myself

${ }^{1}$ For a bibliography of Du Châtelet scholarship see Hagengruber (ed.), 2012. 
and by others, and that the positives of this whirlwind tour nevetheless outweigh the negatives.

Du Châtelet was writing in France in the 1730s, in the wake of Newton's Principia (published in 1687), at a time when Cartesian natural philosophy remained popular in France (Descartes's Principles of Philosophy was published in 1644 and Rohault's textbook of 1671, and multiple editions thereafter, remained the standard Cartesian textbook ${ }^{2}, 3$ ). Both Descartes's and Newton's systems of natural philosophy center around their laws, and in both cases the subject-matter of the laws is "bodies". The question therefore arises as to what these "bodies" are that are the subject-matter of the laws. I call this the "problem of bodies". I begin (in section 2) by outlining the problem of bodies and the solutions available, as things stood at the time Du Châtelet was writing. As we will see, each of the available solutions faced difficulties. This is our entry point into Du Châtelet's philosophy: in section 3 I outline her solution to the problem of bodies, and in section 4 I disucss a difficulty for her solution that arises from gravitational theory. This discussion, in turn, highlights features of her method, which I discuss in section 6. In my opinion, the three major unsolved foundational problems in the wake of Newton's Principia were the problem of bodies, the problem of force, and the issue of appropriate methodology. All three are central to Du Châtelet's text, and in section 5 I offer a few brief remarks on force (a topic which I skipped over even more briefly in my talk).

Sections 2-6 are intended to make a case for the philosophical interest of $\mathrm{Du}$ Châtelet's text, Foundations of Physics, by looking at just some of the elements of that

2 See Shank (2008) for an alternative to the "received narrative" on the reception of Newton in France.

3 According to Zinsser (2009, p. 251, Du Châtelet had access to "Newton's 1726 third edition, but also consulted the 1713 second edition, and the altered Latin version of Book III of the Principia published as De Systemate mundi [System of the World], the 1731 edition. The Jacquier and Le Seur edition of the Principia with its continuous commentary in the annotation was a valuable resource as well." My thanks to Monica Solomon for this. 
text. With this in hand as motivation, section 7 offers a brief introduction to the overall text and to the existing scholarship on this text. In section 8 I end with some remarks on why, despite it's philosophical interest, Du Châtelet's text is largely invisible to philosopers of science today.

\section{The problem of bodies}

In Part II of his Principles of Philosophy (1991, first published in 1644), Descartes set out a project, the goal of which is to explain all the rich variety of the world as we experience it in terms of a very sparse set of resources: matter (which for Descartes is just extension) in motion (i.e. local motion, motion from place to place), moving according to laws (Descartes's three laws of nature, which refer to bodies). The problem of bodies is simply this: What are the "bodies" that are the subject-matter of the laws? By 1740, when Du Châtelet's Foundations of Physics was published, it had become clear that the problem of bodies is a really big problem.

The first issue that we run into in addressing the problem of bodies is that, according to Descartes, bodies are simply "parts of matter", where matter is just "extension", but extension by itself seems to lack any properties or qualities by which it can admit of determinate parts. Thus, at first sight it seems as though Descartes may lack the resources to get an account of bodies off the ground. ${ }^{4} \mathrm{An}$ immediate issue, therefore, is whether there are the resources available within Descartes's project sufficient to constitute bodies that are adequate to serve as the subject-matter of his laws.

Given the resources available in Descartes's project, there are three options for constituting bodies out of extension: (1) use motion and rest; (2) use the laws; (3) modify the account of matter.

The first option, of using motion and rest, is the one adopted by Descartes. He wrote (Principles, II.25): "By one body, or one part of matter, I here understand

\footnotetext{
4 See Brading, 2012, for details of exactly what the difficulties are and how they arise.
} 
everything which is simultaneously transported." This type of solution runs into the following problem: once you allow extension to be divided into parts by motion, it is hard to see how to prevent "division-to-dust" (Garber, 2009, p. 62). It seems that there is nothing to prevent matter dividing and dividing, ad infinitum, and running through our fingers into nothingness. Both Leibniz and Newton worried about this problem, in their different ways, Leibniz maintaining that a part of extension cannot, merely by means of motion and rest, achieve the unity necessary for a body, and Newton maintaining that mere rest among the parts is insufficient for the cohesion of a body. There were other attempts (e.g. Spinoza), but the overall tendency of this approach is towards a fluids account of matter, ${ }^{5}$ in which bodies, if any there are, are derivative ontology rather than primitive, and are therefore not the subject of the basic laws of matter. The upshot is that there was no version of this option available that didn't face serious problems. At best, appeal to mutual motion and rest would need to be supplemented with something else in order to arrive at bodies as primitive material entities.

The second option is to make use of the laws in a constitutive role with respect to their subject-matter. I believe that this was among the approaches adopted by Newton (see Brading, 2012), and I believe that in the end this approach is the best, if not the only, viable philosophical option. However, at the time that $\mathrm{Du}$ Châtelet was writing, even had this option been explicitly on the table (and I know of no evidence that it was), it would not have looked promising. As Marius Stan's recent work has made vivid (see, for example, his "Kant and the Object of Determinate Experience", Philosopher's Imprint, forthcoming, section 1), by the 1730s it was becoming clear to the French mathematicians that the resources of the Principia (especially Newton's second law of motion) were insufficient to handle extended bodies. The force law copes well with point masses, but lacks the resources to deal with the rotation of extended bodies, or with the stresses and strains within them. Du Châtelet was in correspondence with the leading French mathematicians of the period, and knew of their work. Thus, even had she

${ }^{5}$ See, for example, Crockett, 1999. 
considered a law-constitutive approach (and I have no evidence that she did), she would have known that Newton's laws, despite being the most promising laws of mechanics available, nevertheless looked unpromising for a law-constitutive approach to bodies.

The third option is to modify the account of matter as Cartesian extension, and there were various possibilities on the table at the time. By far the most popular was atomism, but this approach carries huge epistemic risk, for the following reason. Consider the following three propositions:

(i) That which is extended is divisible.

(ii) Atoms are extended.

(iii) Atoms are indivisible.

These are mutually inconsistent, so at least one must be rejected. Atomists endorse (ii) and (iii), and reject (i). But on what grounds? There was widespread agreement that extension is conceptually divisible. Therefore, if no reason can be given for denying (i), admitting atoms into our physics carries the risk that we are admitting something unintelligible, and perhaps even self-contradictory, into physics at the outset. In the context of the time (the recent overthrow of the Aristotelian cosmological system, which turned out to have "obvious" yet false propositions at its core; the epistemic crisis of which Cartesian doubt is a part, and so forth), this epistemic risk seemed to many too great a risk to take if other alternatives were available. This is one way to read Du Châtelet's position: atomism carries the risk of incoherence, ${ }^{6}$ and an alternative is to be preferred (of which more below).

A second possibility for modifying matter might be the addition of further essential properties. However, unless there is a finite-sized least part of extension necessary for the instantiation of this property, the division-to-dust problem is not solved by this move. No such properties were on the table at the time.

A third possibility might be the addition of "forces". At the time, there was no settled concept of force, and "force" was being invoked in philosophy in a variety of

\footnotetext{
${ }^{6}$ See Foundations, 7.119-121, where Du Châtelet applies the principle of sufficient reason, as a principle of our knowledge, to the possibility of atoms.
} 
ways to solve a variety of different problems (see section 5, below). If the proposal is to use forces to glue bodies together (thereby attempting to solve the unity and cohesion issues worried about by Leibniz and Newton, for example), this is of course hopeless: unless there are small, finite-sized, parts of extension available to be glued together in the first place, then adding glue into the picture won't help. Another proposal might be to add force to point particles to yield "effective" extension, but this option did not appear until later in the $18^{\text {th }}$ century, and was not available at the time Du Châtelet was writing. Finally, we might include under this general umbrella any proposal to add something non-material to our ontology in order to arrive at extended bodies possessing the required unity and cohesion. The most important example here is Leibniz, and Garber (2009) argues that the "division to dust" problem was one of two key motivations for Leibniz's reintroduction of sustantial forms into his account of bodies. He writes (Garber, 2009, p. 62), "The worries about unity and individuality that ultimately lead Leibniz to the revival of substantial forms in physics seem first to arise in some reflections on views like those of Descartes, for whom matter is indefinitely divisible." As early as 1676, Leibniz stated: "There seem to be elements, i.e. indestructible bodies, because there is a mind in them." ${ }^{7}$

This is how things stood at the time Du Châtelet was writing, in the 1730s: it was clear that all of the available options faced serious problems.

So what? Well, one might think - and Du Châtelet did - that a complete physics would be one which could say what its subject-matter is, so that if it's about bodies it would be able to say what bodies are. So at issue here is what counts as a complete physics: is a complete physics one which can provide an account of its subject-matter, and if so, what are the requirements on such an account?

There is also a much wider significance. At this point in the history of philosophy, science and philosophy had not yet gone their separate ways (they were on the cusp of doing so, and more about that later). What we're looking for, in trying to solve the problem of bodies in early $18^{\text {th }}$ century philosophy, is an account of

\footnotetext{
${ }^{7}$ Quoted in Garber, 2009, p. 64.
} 
bodies in general (not just the bodies of physics). Among the bodies that there are in the world are human bodies. So if we don't have an account of bodies, then we don't have an account of our embodiment in the world, or of our action in the world, and if we don't have these then we can't have either a moral philosophy or a political philosophy. So, as Du Châtelet was acutely aware, the problem of bodies was a much bigger problem than "merely" being a problem for "physics". ${ }^{8}$

With this context in mind, let's turn our attention to Du Châtelet's solution.

\section{Du Châtelet's solution to the problem of bodies}

Du Châtelet accepts the Leibnizian position that in order to have extended bodies we must begin from non-extended simples, on the basis of her worries about material atomism mentioned above (see Foundations, 7.119-122). She argues from non-extended simples to extended bodies as follows (this is a reconstruction; for the argument in her own words see Foundations $7.133^{9}$ ):

\footnotetext{
${ }^{8}$ Du Châtelet's work on bodies in physics is intimately related to her discussions in her manuscript on liberty, and to her contributions to the debate over thinking matter (see Hagengruber, 2012 pp. 47-51) in which she argues against Locke. La Mettrie, in the introductory letter appended to the second edition of his Histoire Naturelle de l'ame (1747) explicitly praised Du Châtelet for clarifying the relations between matter, vitality and mind. The importance of Du Châtelet's work for the debates over vitalism and materialism in the mid-eighteenth century is currently being developed by Phillip Sloan.

${ }^{9}$ Here is the most pertinent extract: "It is again by this dissimilarity [of the monads] that one can understand how non-extended Beings can form extended Beings, for the Elements all exist necessarily one apart from the other (since one cannot ever be the other), and as we have just seen, all of them being united and linked together, an assembly of several diverse Beings results from this and all of them exist apart from the others and by their liaison make a whole; but I have shown that we can only represent as extended an assembly of several diverse, coexisting things that exist
} 
Argument from non-extended simples to extended bodies

(P1): Bodies are composite beings, composed of a multiplicity of non-extended simple beings.

(P2): All simple beings are interconnected (see Chapter 7.130: "All is linked in the world; each being has a relationship to all the beings that coexist with it").

From (P1) and (P2), (C1): Bodies are composed of a multiplicity of interconnected simple beings.

(P3): We necessarily represent a multiplicity as spatially extended (see Chapter 4).

Conclusion (from (C1) and (P3)): We necessarily represent (i.e. represent to ourselves) composite beings (i.e. bodies) as spatially extended.

There's a lot going on in this argument, obviously, but first I also to emphasize why the resulting extended bodies do not face the "division-to-dust" problem. The reason is that Du Châtelet distinguishes between geometrical bodies and physical bodies. For Du Châtelet, geometrical bodies have only potential parts and are divisible to infinity, whereas physical bodies have determinate, finite, actual parts and are not divisible to infinity. This latter is because each extended body arises from a determinate number of simple beings standing in determinate relations to one another: the smallest physical body arises from a determinate number of simples standing in determinate relations to one another, and it cannot be further divided, qua physical body.

The upshot of this argument is that the possibility of bodies as extended is established. For Du Châtelet, bodies are to be extended, non-overlapping, and

apart from each other: therefore, the Leibnizians conclude that an aggregate of simple Beings must be extended. Thus, from the union of the Metaphysics of elements ... flows the union of the Mechanics of Bodies that we see..." (Foundations, 7.133) 
capable of action and reaction by contact. ${ }^{10}$ In order to arrive at an account of such bodies, much more is needed, and Du Châtelet appeals to notions of force in order to complete her account of bodies (see section 5, below), and appeals to mutual motion and rest (see option 1 in section 2, above). ${ }^{11}$ From my perspective, one thing that makes these aspects of her project interesting is reading them as an account of what it takes to make Descartes's project of a physics based on extended bodies in collision viable.

It is immediately and obviously striking how far we have strayed from "physics" into "metaphysics", as we understand these enterprises today. But, as I emphasized in section 2, above, it's not as though there were other unproblematic options out there. We could choose to become quietist, and say "Who knows whether physical science has a coherent subject-matter? Let's just get on and see what we can do". But if we're not prepared to do that, then we have to make one of the above options work, and for Du Châtelet the one that I have just outlined was the best available option.

The argument from non-extended simples to extended bodies outlined above has numerous features worth remarking, including an interesting and highly unusual version of idealism about the extension of bodies, ${ }^{12}$ and the noted

${ }^{10}$ Arriving at bodies that are capable of action and reaction is crucial for $\mathrm{Du}$ Châtelet, not just for her physics, but for her wider concerns with the possibility of human action in the world, and of human liberty. Also crucial for this is an account in which genuine change is possible. For her approach to the latter, see Aaron Wells, "Émilie Du Châtelet on a Wolffian problem of change", ms.

11 What role mutual motion and rest play in Du Châtelet's account of bodies remains to be given detailed consideration. My thanks Jeremy Steeger for pointing out that it does play some role, and for drawing attention to some of the resulting problems for her account.

12 For a discussion of Du Châtelet on extension, space and time, see Monica Solomon, "Émilie Du Châtelet and Christian Wolff on extension, space and time: a comparative analysis", ms. 
distinction between geometrical and physical extension (interesting in the context of discussions of the relationship between the mathematical and the physical). In addition, premise 2 (P2) is part of an extended argument leading to a strong version of Laplacian determinism, several decades before Laplace (of course), and there is a clear historical line that can be traced through Du Châtelet and on to Laplace involving the principles of sufficient reason and continuity. ${ }^{13}$ But I am not going to pursue any of these here. Instead, one of the things that is very interesting about $\mathrm{Du}$ Châtelet's Foundations of Physics is the interplay between metaphysics and physics, and her awareness of how the details of the physics bear on the metaphysics. The two main examples in her text are her engagement with the vis viva controversy ${ }^{14}$ and her discussion of gravitation. The latter is the subject of the next section.

\section{A difficulty for Du Châtelet's solution arising from gravitational theory}

Some context is again helpful in order to understand the significance of what Du Châtelet is doing. At the time she was writing, vortex theories of gravitation remained a live competitor to Newtonian gravitation. Newton had argued in the Principia for his universal theory of gravitation, in which gravity acts particle-toparticle, writing (Principia, Book 3, Proposition 7, Corollary 1): ${ }^{15}$

"Therefore the gravity toward the whole planet arises from and is compounded of the gravity toward the individual parts."

\footnotetext{
13 For the principles of sufficient reason and continuity in relation to Laplacian determinism see van Strien, 2014. For Du Châtelet on continuity see John Hanson, "Du Châtelet on continuity", ms.

14 On the so-called "vis viva controversy", see Hankins, 1965; Iltis, 1970; Laudan, 1968; and Papineau, 1977.

15 References to Newton's Principia are to Cohen and Whitman, 1999.
} 
Huygens (and other proponents of vortex theory) rejected this last step in the argument, maintaining that the phenomena of gravitation arise by local action of particles in contact with other particles.

Du Châtelet's account of bodies favors action by contact and therefore vortex theory. However, for Du Châtelet this is not sufficient to decide the issue between Newtonian and vortex theories of gravitation. Having introduced the two approaches, Du Châtelet turns to the empirical evidence, and considers two arguments.

The first argument concerns the planetary trajectories. In Book 2 of the Principia, Newton had argued that if the matter making up the vortex is of the same kind as the matter making up the planets, and is therefore subject to Newton's laws of motion, then "the hypothesis of vortices can in no way be reconciled with astronomical phenomena." 16 Huygens responded by rejecting the idealizations and assumptions about fluids that Newton used in making the argument go through. He offered instead a vortex theory recovering the trajectories of the planets. ${ }^{17}$ Supposing this successful, the upshot is that empirical evidence does not distinguish between Newtonian universal gravitation and vortex theory for planetary trajectories.

Du Châtelet then moves on to a second argument, concerning the shape of the Earth. She notes that the two approaches, Newtonian universal gravitation and Huygens' vortex theory, give rise to different predictions in this case. She writes (Foundations, 15.379):

M. Huygens believed the gravity to be the same everywhere [because it pertains to the body considered as a whole], and Newton assumed it to be different in different places on earth and dependent on the mutual attraction of the parts of matter: the only difference between them is the shape they

16 Principia, Book 2, Section 9, Scholium to Proposition 53.

${ }^{17}$ Huygens, 1690. 
attribute to the earth - since from M. Newton's theory arises a greater flattening than from that of M. Huygens.

So she is very clear about the difference between the two approaches being due to the disagreement over universal gravitation (i.e. whether it is particle to particle or not), and on where the observational consequences differ. She is also up-to-date with the efforts to measure the shape of the Earth, and reports that she is awaiting further results that will help determine the question between Huygens and Newton. She reports the initial results from the measurements taken on the expedition to the pole led by Maupertuis, as follows (Foundations, 15.384):

The one that comes from the measurements at the Pole is approximately as the one that M. Newton had determined with his theory. Thus, it is true to say that M. Newton made great discoveries owing to the measurements and observations of the French and that he will most likely receive confirmation.

In short, by the 1730s, the empirical evidence on the shape of the Earth favored Newtonian universal gravitation.

This situation puts enormous pressure on the concept of body as extended and impenetrable. The empirical evidence favors an account of gravitation in which the effects of gravity arise not from each body considered as a bulk whole but from every particle of every body interacting with every other particle: the interior particles of a body seemingly interact with one another and with the interior particles of distant bodies, dependent on the distances of the particles from one another and not at all on whether they are located within the body or on its surface. How could a fluids account reproduce this? Certainly, it would require the fluid to flow through pores in the body, without penetration of the particles making up the body, reaching every tiny particle and affecting its behavior in such a way as to recover the predictions of universal particle-to-particle interaction. The threat is that no pores could ever be sufficiently fine-grained, and no fluid flow could be 
achieved through such pores, such as to mimic the effects of universal gravitation. Here is d'Alembert, some decades later in the Encyclopedia, expressing the problem:

Now, if there is matter that continually pushes the bodies, it must be that this matter is fluid and subtle enough to penetrate the substance of all the bodies: but how can a body that is subtle enough to penetrate the substance of the hardest bodies and rarified enough to not be perceptibly opposed to the movement of bodies, push considerable bodies toward each other with so much force? How does this force increase following the proportion of the mass of the body that the other body is pushed towards? Where does it come from that all bodies, in supposing the same distance and the same body towards which they tend, move with the same speed? Finally, as regards a fluid that only acts on the surface, whether that be of the bodies themselves or their interior particles, how can it communicate to the bodies a quantity of movement that follows exactly the proportion of the quantity of matter enclosed in the bodies?

What Du Châtelet made clear in her Foundations is that the empirical crux of this issue arises from considerations of the shape of the Earth.

Returning to Du Châtelet's text, she ends her discussion of Newtonian gravitation as follows (Foundations, 16.399):

"[It remains] to be examined if some subtle matter is not the cause of this phenomenon... perhaps a time will come when we will explain in detail the directions, movements, and combinations of fluids that operate the phenomena that the Newtonians explain by attraction, and that is an investigation with which the physicians must occupy themselves.

Why does she say this? Why doesn't she simply accept the empirical evidence against vortex theory and adopt Newtonian universal gravitation? One reason is surely the apparent conflict with her solution to the problem of bodies. Her account demands bodies that are extended and impenetrable, yet universal gravitation 
works with point particles interacting via a force that is particle-to-particle, independent of that particle's location within or on the surface of a body. A second reason has to do with her methodology of science. Her discussion of methodology is the subject of section 6 , at the end of which I return to the case of gravitation.

\section{The problem of force}

I have said that, in my opinion, the three major unsolved philosophical problems in the foundations of physics in the wake of Newton's Principia are the problem of bodies, the problem of force, and the issue of appropriate methodology for pursuing the project. As is well known, Descartes officially excludes any notion of force from his physics, yet that physics is replete with phrases which seem to imply some such notion.

At the time Du Châtelet was writing there was no stabilized concept of force, and it remained controversial whether any notion of force should be included in physics. So far as I can tell, there were three distinct possible roles for force that were being worked through by the late seventeenth century, and in the context of which concepts of force were being articulated. The first is in providing extended regions of matter in attempts to solve "problem of bodies". As noted above, a Leibnizian move is to invoke a notion of force as providing the unity and stability to a region of matter necessary for that region to be a body.

The second role is as a source of activity in the world. It is one thing to solve the problem of bodies so that there can be passive material bodies in the world. It is another to provide bodies which are capable of acting on one another. Moreover, whether and how to make a distinction between action and passion, and between active force and passive force, is an issue of dispute in the attempts to work out a concept of force adequate to the demands of post-Cartesian philosophy.

The third role for force is in solving the problems of mechanics, in which the ability of one body to affect the motion of another body has to be theorized in such a way as to allow the solution of the problems of mechanics, including first of all collisions but then other problems too. Articulating this role involved further 
distinctions between, for example, inertial force, impressed force, centripetal force, force of resistance, and so forth. ${ }^{18}$

Different philosophers differed over which of these problems they attempted to address, and the extent to which they saw these problems as inter-related. They differed, therefore, in what constraints they saw on an adequate conception of force. For example, Newton was concerned only with the third problem, whereas Leibniz wanted to develop concepts of force that addressed both the first and the third, and Du Châtelet sought to address all three. At least part of Du Châtelet's motivation was to ensure the possibility of human bodily action, as a necessary condition for the possibility of free human action, so we glimpse here one aspect of the wider implications of the discussions over developing an appropriate concept of force.

Du Châtelet's text contains an extended elaboration of force in relation to bodies, with the goal being to arrive at bodies which are extended, impenetrable, and capable of action and reaction, such that they can (among other things) serve as the subject-matter of Newton's laws (which also involve forces) or modified versions thereof. To what extent she is successful requires detailed evaluation. ${ }^{19}$

These brief remarks on the problem of force also conclude what I want to say about the problem of bodies in this paper. In a way, it's an unsatisfactory place to end because I have not offered a solution to the problem of bodies. However, this is not surprising. The difficulties in solving the problem of bodies, indeed the failure to find a general solution, is one of the key issues that drives the split between philosophy and physics that emerges in the $18^{\text {th }}$ century.

\section{Du Châtelet on method}

Some context is once again helpful for understanding the significance of Du Châtelet's discussion, this time of method. At the time Du Châtelet was writing, there

\footnotetext{
${ }^{18}$ See McMullin, 1978.

${ }^{19}$ In this context, see Jeremy Steeger, "PSR and the problem of force: the metaphysical grounding of physics in Du Châtelet and Wolff", ms.
} 
were widespread and deep divisions over methodology. Du Châtelet was familiar with the Cartesian method of hypothesis; she had read the Leibniz-Clarke correspondence and so would have seen the deep differences over methodology exhibited in the disagreements between Leibniz and Clarke, and would have been aware of Leibniz's use of his principle of sufficient reason as an inviolable constraint on all physical theorizing. Also on the table were Newton's sparse remarks about methodology in the Principia, including his Rules of Reasoning and "hypotheses non fingo", along with his approach to method in the Opticks, which might seem somewhat different from that in the Principia, at least superficially. Looming large in the background are also Bacon and Boyle in England, and Huygens in France (Huygens had offered a hypothetico-deductive approach). At stake were such fundamental questions as "What principles should be used to constrain theorizing?"; "What interplay should there be between these principles and empirical evidence?"; "What should the role(s) of hypotheses be?"; "What criteria should be used for assessing hypotheses?".

Du Châtelet offers the following assessment of the state of Cartesian physical science in France. She says that despite Descartes's many important contributions to physics, as a result of features of his method "the books of philosophy, which should have been collections of truths, were filled with fables and reveries" (Foundations 4.55). She says that an improved methodology is needed.

In what follows, I will put in front of you some of what Du Châtelet says, and let the text speak for itself. I think you will agree with me that a several aspects of what she says sound remarkably familiar from twentieth century philosophy of science, and remarkably modern.

First of all, Du Châtelet tackles the "principles of knowledge". She says that we must reject Descartes's criterion of "clear and distinct ideas" as a principle of knowledge. She writes (Foundations, 1.2):

This method, moreover, would only serve to perpetuate disputes, for among those with opposing views, each has this lively and internal sense of what 
they put forward. Thus, no one has to yield, since the evidence is equal on the two sides.

She argues that instead we should follow Leibniz and adopt the principle of contradiction and Leibniz's principle of sufficient reason, writing (Foundations, 1.4 \& 1.8):

[T] he source of the majority of false reasoning is forgetting sufficient reason, and you will soon see that this principle is the only thread that could guide us in these labyrinths of error the human mind has built for itself in order to have the pleasure of going astray.

So we should accept nothing that violates this fundamental axiom; it keeps a tight rein on the imagination, which often falls into error as soon as it is not restrained by the rules of strict reasoning.

With this in place, in Chapter 4 of the Foundations she turns her attention to hypotheses. ${ }^{20}$ She argues that the Cartesians admit too many hypotheses (this is the context for the quote above about fables and reveries), whereas the Newtonians admit too few (i.e. none). She argues that by looking at how the sciences have in fact progressed, hypotheses play important heuristic roles:

Descartes, who had established much of his philosophy on hypotheses ... gave the whole learned world a taste for hypotheses; and it was not long before these fell into fictions. Thus, the books of philosophy, which should have been collections of truths were filled with fables and reveries. (4.55)

\footnotetext{
${ }^{20}$ See Hagengruber, 2012, pp. 16-25, and the current research of Anne-Lise Rey, for Du Châtelet on hypotheses. For a discussion of Du Châtelet and Descartes on hypotheses, see Detlefsen, "Du Châtelet and Descartes on the Roles of Hypothesis and Metaphysics in Natural Philosophy", forthcoming.
} 
M. Newton, and above all his disciples, have fallen into the opposite excess... (4.55)

If we take the trouble to study the way the most sublime discoveries were made, we will see that success came only after many unnecessary hypotheses... for hypotheses are often the only available means to discover new truths. (4.57)

Hypotheses must then find a place in the sciences, since they promote the discovery of truth and offer new perspectives... (4.58)

She argues that we must admit hypotheses into scientific theorizing, and that we must adopt must stronger criteria for assessing them. She writes:

Without doubt there are rules to follow and pitfalls to be avoided in hypotheses. The first is, that it not be in contradiction with the principle of sufficient reason, nor with any principles that are the foundations of our knowledge. The second rule is to have certain knowledge of the facts that are within our reach, and to know all the circumstances attendant upon the phenomena we want to explain. This care must precede any hypothesis invented to explain it; for he who would hazard a hypothesis without this precaution would run the risk of seeing his explanation overthrown by new facts that he had neglected to find out about. (4.61)

Du Châtelet emphasizes exploring the empirical consequences of a theory, and not merely seeking consistency with prior observations:

If it is found that these experiments confirm it, and that it not only explains the phenomenon that one had proposed to explain with it, but also all the consequences drawn from it agree with observations, its probability grows to such a point that we cannot refuse our assent to it... (4.58) 
Thus, acceptance of a hypothesis depends on all its consequences agreeing with observations, not just those observations for which it was originally constructed.

Du Châtelet argues that there is an asymmetry between acceptance and rejection (falsification) of a theory:

One experiment is not enough for a hypothesis to be accepted, but a single one suffices to reject it when it is contrary to it. (4.64)

And, she emphasizes selective falsfication (i.e. we must take care over which aspects of a hypothesis are falsified by a contrary experiment):

Thus, in making a hypothesis one must deduce all the consequences that can legitimately be deduced, and next compare them, with experiment; for should all these consequences by confirmed by experiments, the probability would be greatest. But if there is a single one contrary to them, either the entire hypothesis must be rejected, if this consequence follows from the entire hypothesis, or that part of the hypothesis from which it necessarily follows. (4.66)

And the final aspect of her discussion of hypotheses that I will highlight here is her condition of no ad hoc modifications as a condition on a good hypothesis:

it is necessary... that the phenomenon result necessarily, and without the obligation to make new suppositions...

When the necessary consequences do not follow from it, and to explain the phenomenon, a new hypothesis must be created in order to use the first, this hypothesis is only a fiction unworthy of a philosopher. (4.69)

The upshot is a methodology in which there is an interesting inter-play between the principles of our knowledge (the principle of contradition, PSR, the law of continuity (which she derives from PSR), and empirical evidence (in which, as we have seen, 
she includes the working out of the detailed empirical consequences, and being disciplined about acceptance and rejection of hypotheses).

We have seen this methodology at work in the gravitation example discussed above. In the case of gravitation, the hypotheses of Newton and Huygens were assessed with respect to detailed empirical consequences, as well as with respect to whether they are consistent with an account of bodies that satisfies the principles of our knowledge (is not self-contradictory). Moreover, while I did not discuss this above, Du Châtelet also argues that Newtonian action-at-a-distance fails to satisfy the principle of sufficient reason, and is therefore problematic. ${ }^{21}$ As we saw, in concluding her discussion of gravitation (Foundations, 16.399), she urges "physicians" to seek a fluids account of Newtonian attraction. However, importantly, her methodology does not allow us to entertain, let alone accept, the suggestion that there is such a fluid as a scientific hypothesis in the absence of detailed empirical implications of that hypothesis. The proposal of such an "ether", unaccompanied by detailed empirical implications, would be a mere "fiction unworthy of a philosopher".22

Thusfar, I have sought to persuade you of two things. First, that the problem of bodies is a really big problem, one that's central to Du Châtelet's text, and one that's an important lens through which to understand how and why the split between philosophy and physics came about (see sections 2-5, above). And, now, by putting some elements of Du Châtelet's discussion of methodology in front of you, I have offered a second example of the interest of her text for philosophy of science,

${ }^{21}$ See Jamee Elder, "Émilie du Châtelet on Newtonian Attraction", ms. ${ }^{22}$ As both Steven French (in Q\&A) and Phil Sloan have emphasized, more needs to be done to examine in detail the relationship between Du Châtelet's statements on hypotheses and the chapters in which she engages with contemporary physics. In addition to her discussion of gravitation, Du Châtelet's engagement with the vis viva controversy also exhibits features of her methodology; both deserve closer scrutiny in relation to her explicit methodological commitments. 
and the importance of her text in the history of philosophy of science. ${ }^{23}$ More is needed to make the case, of course, but my hope is that what I have said here is sufficient to encourage the view that it's worthwhile for philosophers of science to take a look at this text more closely.

\section{Du Châtelet's Foundations of Physics: an overview}

In this section of the paper, I offer a brief introduction to the overall text of $\mathrm{Du}$ Châtelet's Foundations of Physics, and to the existing scholarship on this text.

Du Châtelet has two major published works. Her Foundations of Physics (translated from Institutions de Physique) was first published in 1740. It was reprinted in London and in Amsterdam, and a second edition was published in 1742. The second edition was translated into German (1743) and Italian (also in 1743). ${ }^{24}$ While the historical work remains to be done on the reception and dissemination of the Foundations, this information about the editions already indicates that the text was read, and that it was read not only in France but also beyond. I noted above that her discussion of hypotheses was reproduced in the Encyclopedia of Diderot and

\footnotetext{
${ }^{23}$ Familiar as much of her discussion of scientific method sounds to present-day ears, we might wonder whether her text in fact has any connection to later discussions. I offer a few words about dissemination of her text in section 7, but it is perhaps worth remarking here already that her discussion of hypotheses was reproduced in the highly influential Encyclopedia of Diderot and d'Alembert. ${ }^{24}$ Everything in this paper is based on the 1740 edition. In addition to the published versions, there is a partial manuscript (for details see Barber, 1967, reprinted with discussion in Hayes and Zinsser 2006; and Janik, 1982). Much work is to be done before we have a scholarly edition of the Foundations available.
} 
d'Alembert, and there a multiple entries in the Encyclopedia that were taken from the Foundations, sometimes with attribution and sometimes without. ${ }^{25}$

Du Châtelet's second major publication, which came out after her death (Du Châtelet died young, at the age of 42), was her translation of Newton's Principia along with her commentary. This also went through two editions (1756 and 1759). According to George Smith, I. B. Cohen said that the only other translation he and Anne Whitman made use of in preparing their own was that of Du Châtelet. They used it in places where they found Newton's latin ambiguous, because they found Du Châtelet's rendering in French reliable (and this is, of course, a strong indication that she had a thorough understanding of what she was reading and translating).

In addition to these publications, there are also various other shorter publications and manuscripts, including work on heat and fire, on optics, on liberty and on the bible. ${ }^{26}$

At the time that Du Châtelet was writing her Foundations, Cartesian natural philosophy remained popular in France, with Newtonian physics yet to take hold beyond mathematical circles, ${ }^{27}$ and Leibnizian metaphysics was unknown in France. Du Châtelet wrote:

[I]t is surely very unfortunate that the opinions of Newton and of Descartes have become a sort of national affair. About a book of physics one must ask if it is good, not if the author is English, German, or French.

\footnotetext{
${ }^{25}$ See Maglo, 2008, "Mme Du Châtelet, l'Encyclopedie, et la philosophie des sciences", and Anne Seul, "Du Châtelet, Formey, and the Encyclopedia of Diderot and D'Alembert", ms.

${ }^{26}$ See Zinsser, ed., 2009, and references therein.

27 Shank (2008) disputes the "received narrative" from the mid $18^{\text {th }}$ century of the reception of Newton in France. He offers an extended treatment tracing the presence of Newtonian ideas in France from the late $17^{\text {th }}$ century through to the late $18^{\text {th }}$ century.
} 
Du Châtelet sought to bring together Descartes, Leibniz and Newton into a systematic whole, investigating whether, through drawing from each, a viable philosophical approach to physical science could be found. In the process, she addresses what I believe to be the three major unsolved foundational issues in physical science at the time: bodies; force; and method. We have seen something of her engagement with each.

Writing for a French audience, Du Châtelet begins with Descartes as the presupposed background, and then sets out to introduce a French audience to Leibnizian and Newtonian ideas. Her interest is in the physical, metaphysical, and epistemological viability of the whole (Foundations, Avant-Propos):

Physics is an immense building that surpasses the powers of a single person. Some lay a stone there, while others build whole wings, but all must work on the solid foundations that have been laid for this edifice in the last century, by means of geometry and observations; still others survey the plan of the building, and I, among them.

The text is pedagogical (it is addressed to her son), ${ }^{28}$ epistemological and methodological, and it is systematic (surveying the plan of the whole, and integrating disparate elements into a viable whole). The topics covered include:

- the principles of our knowledge

- the existence of God

- essence, attributes and modes

- hypotheses

- space and time

- the elements of matter and the nature of bodies

${ }^{28} \mathrm{Du}$ Châtelet is explicit about this, and the clarity of writing and plentiful examples reflect this claim. That said, Du Châtelet published her book into the public intellectual realm, and the appropriate genre and intended audience through which to understand her book remain open questions in the literature. 
- the divisibility and subtlety of matter

- the shape and the porosity of bodies

- motion and rest

- gravity, falling bodies, the pendulum, projectiles

- Newtonian gravity and attraction

- dead and living forces of bodies

With all of this in mind, you might be wondering why this text is not better known, and why you haven't come across the secondary literature. The existing scholarship on Du Châtelet falls into two groups. The first category is enormous: there is a vast literature on Du Châtelet in relation to Voltaire. The primary focus of this literature is Voltaire, and it contains assessments of her work such as the following, from the 1960s:

Remarkable in its historical context as her achievement is, we should perhaps accept her own verdict that it was by means of translation and exposition rather than original work that she was best equipped to help the cause of enlightenment. It seems unlikely, then that in this sphere she can have exerted any real influence on Voltaire's thought...

In my opinion, this is false, false, and false. First, this is not how she evaluated her own work. She did make self-deprecating remarks from time to time, but these need to be read in context, and other remarks she makes about how she thought of her own work also need to be taken into account. Second, if one reads this text as a philosophical text, it is immediately obvious that it is not "merely" translation and exposition. A great deal of very interesting philosophy is being done. Finally, on the question of her influence or otherwise on Voltaire's thought, I chose not to comment at the conference, but recent scholarship is directly challenging this view (see Zinsser, 2007, and Hagengruber (ed.), 2012, and references therein) and in Q\&A 
Mauricio Suarez reported on a recent workshop in Oxford at which significant influence was claimed. ${ }^{29}$

The second category, in which Du Châtelet is read as a philosopher in her own right, is small, especially if we restrict ourselves to English-language scholarship. ${ }^{30}$ Of particular note are, I think, are papers by Iltis (1977); Janik (1982); Hayes (1999); and Hutton (2004). There are two edited collections, Zinsser and Hayes (2006) and Hagengruber (2012), containing a rich variety of papers, and full bibliographies can be found by consulting these volumes. Hagengruber and her group are actively working on the philosophy of Du Châtelet. Of enormous importance is that Isabelle Bour and Judith Zinsser (Zinsser, ed., 2009) succeeded in publishing with Chicago University Press a translation of selections of Du Châtelet's philosophical writings, including approximately a third of the Foundations. Detlefsen (2013) provides us with a Stanford Encyclopedia of Philosophy entry on Du Châtelet, and she and Janiak are engaged in a major research project on the philosophy of Du Châtelet. Finally, I am part of a small group at Notre Dame working

${ }^{29}$ The above quotation is from Barber, 1967, who was one of the first scholars to work on Du Châtelet as a major figure of the French Enlightenment (see Zinsser and Hayes, 2006, p. 3). William Barber was not only an important scholar of the French Enlightenement, he was also kind to me personally when I was a graduate student, and I mean him no disrespect in using his words in this way: my point is that the focus on Voltaire, and on the question of Du Châtelet's influence on Voltaire, by Enlightenment scholars has obscured the view for philosophers whose primary interest is in the Foundations of Physics as a philosophical text. This we need to overcome if we are to recover Du Châtelet as a figure in the history of philosophy. ${ }^{30}$ My aim here is to draw attention to the small amount of work in English. The French-language and German-language scholarship on Du Châtelet as a philosopher is important, and bibliographies to the full range of scholarship are to be found in the references that follow. 
on Du Châtelet's Foundations of Physics, on both research papers and on completing a full translation. ${ }^{31}$ So there is momentum here, and some cause for optimism.

\section{Recovering the text}

\subsection{Paradigms}

Why is the Foundations of Physics so invisible to us, as philosophers of science, today? Surely, there are sociological and political reasons for this, but I am not going to discuss those here. Instead, I want to highlight one of the philosophical reasons for the invisibility: treating Newtonian physics as a Kuhnian paradigm makes $\mathrm{Du}$ Châtelet's Foundations of Physics invisible. Here's why:

If we think of the early $18^{\text {th }}$ century French Newtonians as already working within a Newtonian paradigm, then we're going to think of certain questions as already having been answered, and we're going to view their work from the perspective of normal science (articulating the theory, solving problems within the theory, "matching of facts with theory" to quote Kuhn). What that does is make invisible some of the key problems left unsolved in the wake of the Principia, including the things discussed in sections 2-6 of this paper.

To see this more clearly, let's begin from the following quote from Kuhn:

Effective research scarcely begins before a scientific community thinks it has acquired firm answers to questions like the following: What are the fundamental entities of which the universe is composed? How do these interact with each other and with the senses? What questions may

\footnotetext{
${ }^{31}$ We are working on a complete translation of the 1740 first edition, drawing on only the published 1740 text and the partial manuscript (our work on the latter is being led by Lauren LaMore). A great deal more work by more people will be needed in order to take into account the later editions and translations of the text.
} 
legitimately be asked about such entities and what techniques employed in seeking solutions?" (Kuhn, Structure, pp. 4-5)

None of these questions had answers at the time that Du Châtelet was writing, 50 years after the Principia. The early $18^{\text {th }}$ century was dealing with deep and important problems about what a body is, how there can be action in the world, and about how best we can mobilize empirical means to address our philosophical questions, be they physical or metaphysical.

The point I want to stress is this: we know that there are advantages and disadvantages of thinking in terms of paradigms, and that one of the disadvantages is all the things that become invisible. We need to be very aware that if we apply the notion of a "Newtonian paradigm" to the early $18^{\text {th }}$ century, then we are using it as a weapon of power that makes certain kinds of work very visible, and other kinds of work irrelevant and invisible. ${ }^{32}$ Specifically, if we treat Newtonian physics as a Kuhnian paradigm established soon after the publication of Newton's Principia, this makes everything I talked about in sections 2-6 above, invisible.

\subsection{Revolutions}

I want to give the last word to Du Châtelet, and for that I am going to turn from scientific paradigms to scientific revolutions. According to the Stanford Encyclopedia of Philosophy entry on scientific revolutions (Nickles, 2014), the idea of a scientific revolution had its origins in $18^{\text {th }}$ century France, with Clairaut, d'Alembert, and Diderot. Cohen (1985) and more recently Hacking (2012) credit Kant with originating the idea, according to SEP.

Du Châtelet's 1740 text predates Clairaut, d'Alembert and Diderot. Also, Du Châtelet employed Clairaut to teach her mathematics in the 1730s when he was a teenager, and large chunks of Du Châtelet's book ended up in the Encyclopedia of Diderot and D'Alembert. Kant comes after Du Châtelet, and we know that Kant read

${ }^{32}$ See, for example, Stan, forthcoming, on classical mechanics. 
at least some of her work. ${ }^{33}$ With this in mind, consider the following passages from Du Châtelet's Foundations (Avant-Propos, V):

I will not write for you here the history of the revolutions experienced by physics; a thick book would be needed to report them all. I propose to make you acquainted less with what has been thought than with what must be known....

Up to the last century, the sciences were an impenetrable secret... Descartes appeared in that profound night like a star come to illuminate the universe. The revolution that this great man caused in the sciences is surely more useful, and perhaps even more memorable, than that of the greatest empires...

The comparison with political revolutions is there, and the idea is explicitly applied to the sciences and to physics. So if we're going to include some history of the

${ }^{33}$ When I first opened the Selected Philosophical and Scientific Writings of Du Châtelet (Zinsser, ed., 2009), I was immediately struck by the apparent overlap between topics treated by Du Châtelet and by the early Kant. Kant's first publication (1749) was his contribution to the so-called "vis viva controversy", and this same topic occupies the final chapters of Du Châtelet's Foundations as part of a public dispute. Kant is explicitly continuing this debate. Du Châtelet submitted her "Dissertation on the Nature and Propagation of Fire" in 1737 for the 1738 Royal Academy of Sciences prize competition, and Kant published in 1755 on fire. Reading on, the similarities seem much deeper and more important than this. Schönfeld's (2000, Introduction) description of Kant's precritical project could be a description of what Du Châtelet sets out to do in her Foundations (and related texts, such has her manuscript "On Liberty"). It seems there is much work to be done on the relationship between Du Châtelet's Foundations of Physics and Kant's early philosophy. 
concept of scientific revolutions in our philosophy of science classes, then let's include Du Châtelet. ${ }^{34}$

\section{Conclusions}

My talk ended there, giving Du Châtelet the last word, but since this is a paper it is perhaps worth re-stating the main points that I have sought to bring out.

I believe that Du Châtelet's Foundations of Physics is an interesting and important text in the history of philosophy of science. I have provided evidence for this by looking at two topics: the problem of bodies and scientific method.

I began the paper by arguing that the problem of bodies was a significant problem at the time Du Châtelet was writing, and then argued that this problem is central to Du Châtelet's text. I also claimed that the problem of bodies is an important lens through which to understand how and why the split between philosophy and physics came about. I outlined her solution to the problem of bodies, and discussed a problem that her solutiuon faces. I believe that the manner in which she addressed this problem is an illustration of the method that she explicitly develops and advocates, and in section 6 I presented the most important features of this method.

Finally, I suggested that treating Newtonian physics as a Kuhnian paradigm established soon after the publication of Newton's Principia makes all of the above invisible, and that is one philosophical reason why her work is largely invisible to us today, as philosophers of science. I am delighted to be contributing to the recent upswing of interest in Du Châtelet among philosohers. Long may it continue.

\section{Acknowledgements}

\footnotetext{
34 I had a very nice email exchange with Tom Nickles, author of the SEP entry on scientific revolutions, and he will be updating his entry to include Du Châtelet. Thank you, Tom!
} 
This paper is part of the work on Du Châtelet's Foundations of Physics being undertaken by a research group at the University of Notre Dame, whose members include Jamee Elder, John Hanson, Lauren LaMore, Anne Seul, Phillip Sloan, Monica Solomon, Jeremy Steeger, and Aaron Wells. I am grateful to them all for their work, for our many discussions, and for their contributions to this paper. My thanks to those who offered comments and criticisms on aspects of this work that were presented at the universities of Knoxville (February 2015) and Princeton (March 2015). Finally, my thanks also to the organizers of the BSPS conference for inviting me to speak, without which the talk that forms the basis of this paper would never have come into being, and to the participants at the conference for their questions, contributions, and encouragement.

\section{References}

Barber, W. H., 1967. "Mme Du Châtelet and Leibnizianism: the genesis of the Institutions de Physique", in The Age of the Enlightnment: studies presented to Theodore Besterman. Reprinted with slight revisions and updated references, and accompanying discussion, in Zinsser and Hayes, eds., 2006.

Brading, K., 2012. 'Newton's law-constitutive approach to bodies: a response to Descartes', in Interpreting Newton: critical essays, ed. A. Janiak \& E. Schliesser, Cambridge University Press.

Cohen, I. B., 1985. Revolution in Science. Cambridge: Harvard University Press.

Cohen, I. B., and Whitman, A., 1999, The Principia: Mathematical Principles of Natural Philosophy: A New Translation. Berkeley: University of California Press.

Crockett, T. ,1999. Continuity in Leibniz's Mature Metaphysics. Philosophical Studies, 94(1), 119-138. 
Detlefsen, K., 2013. "Émilie du Châtelet", The Stanford Encyclopedia of Philosophy (Summer 2014 Edition), Edward N. Zalta (ed.), URL = <http://plato.stanford.edu/archives/sum2014/entries/emilie-du-chatelet/>.

Detlefsen, K., forthcoming. "Du Châtelet and Descartes on the Roles of Hypothesis and Metaphysics in Natural Philosophy".

Descartes, R., 1991. Principles of Philosophy, trans. V. R. Miller and R. P. Miller, Kluwer.

Du Châtelet, E., 1740. Institutions de Physique (translated as Foundations of Physics). English translation of several chapters is available in ed. Zinsser, 2009.

Garber, D., 2009. Leibniz: Body, Substance, Monad. Oxford University Press.

Hacking, I., 2012. "'Language, Truth and Reason' 30 Years Later," Studies in History and Philosophy of Science A 43: 599-609.

Hagengruber, R. 2012, "Emilie du Châtelet between Leibniz and Newton: the transformation of metaphysics", in Hagengruber, ed., 2012.

Hagengruber, R., ed., 2012. Emilie du Châtelet between Leibniz and Newton. Springer.

Hankins, T. L., 1965, "Eighteenth-Century Attempts to Resolve the Vis viva controversy", Isis 56, 281-297.

Hayes, J. C., 1999. "Physics and figuration in du Châtelet's 'Institutions de physique',, in Reading the French Enlightenment: System and Subversion, ed. J. C . Hayes, Cambridge: Cambridge University Press. 
Hayes, J. C.,and Zinsser, J. P., eds., 2006. Emilie Du Châtelet: rewriting Enlightenment philosophy and science. Oxford: Voltaire Foundation.

Hutton, S., 2004. "Emilie Du Châtelet's Institutions de physique as a Document in the History of French Newtonianism". Studies in history and philosophy of science A, $35,515-31$.

Huygens, C. 1690. Discours de la cause de pensanteur.

Iltis, C., 1970. "D'Alembert and the vis viva controversy". Studies in History and Philosophy of Science 1, 135-144.

Iltis, C., 1977. "Madame du Châtelet's Metaphysics and Mechanics". Studies in History and Philosophy of Science 8, 29-48.

Janik, L. G., 1982. "Searching for the metaphysics of science: the structure and composition of madame Du Châtelet's Institutions de physique, 1737-1740.

Kuhn, T. S., 1962. The Structure of Scientific Revolutions. University of Chicago Press.

Laudan, L., 1968. The Vis viva controversy: a post-mortem. Isis 59, 130-143.

Maglo, K., 2008. “Mme Du Châtelet, l'Encyclopedie, et la philosophie des sciences", in Émilie du Châtelet: éclairages et documents nouveaux, Paris, FerneyVoltaire: CIEDS, 2008, 255-66.

McMullin, E., 1978. Newton on Matter and Activity. Notre Dame: University of Notre Dame pRess. 
Nickles, T. "Scientific Revolutions", The Stanford Encyclopedia of Philosophy (Summer 2014 Edition), Edward N. Zalta (ed.), URL = <http://plato.stanford.edu/archives/sum2014/entries/scientific-revolutions/>.

Papineau, D., 1977. “The vis viva controversy: do meanings matter?". Studies in History and Philosophy of Science 8, 111-142.

Shank, J. B., 2008. The Newton Wars and the Beginning of the French Enlightenment. Chicago: University of Chicago Press.

Stan, M., forthcoming. "Kant and the Object of Determinate Experience", Philosopher's Imprint.

Van Strien, M., 2014. "On the origins and foundations of Laplacian determinism", Studies in History and Philosophy of Science 45, 24-31.

Zinsser, J., 2006. La Dame d'Esprit: A Biography of the Marquise Du Châtelet. Viking Penguin. Republished 2007 as Emilie Du Châtelet: Daring Genius of the Enlightenment. Penguin.

Zinsser, J., ed., 2009. Emilie Du Châtelet: Selected Philosophical Writings. Trans. I. Bour and J. Zinsser. Chicago: Chicago University Press. 